\title{
Establishment of Learning Environment under the Integration of Physical Education Design
}

\author{
Kaiwen Li \\ School of Physical Education \\ Wenshan University \\ Wenshan, Yunnan, China 633000
}

\begin{abstract}
Physical education design is a complex process. It can make the effects of students' application of knowledge and skills more optimized through integrating design philosophy and value orientation of design to establish learning environments for individuals or groups.
\end{abstract}

Keywords -physical education; design; orientation; integrate; establish

\section{PhysicAl EDUCATION DESIGN}

\section{A. Design and Physical Education Design}

In the research field of instructional design, the main investigator who emphasizes the designing direction of instructional design is Rowland. [1] Rowland points out that design is the research on creating some kind of new things that have actual utility. Physical education design is a subsystem of design, so characteristics of design also suit physical education design. Physical education design is put forward for the specific objective of students' physical and mental health. When carrying out physical education design, teachers' instructional design bases on the overall understanding of physical education discipline, starts from here and comprehensively considers gym teacher, students, field and facilities, teaching environments of physical education and learning results and development goals that need achieving. The class teaching of physical education is complex, rapid and unpredictable. [2] Teachers must make rapid response to various situations and teaching events happened in teaching, make pointed references to design action plan of teaching to solve these problems, and use idea, awareness and knowledge and skills in physical education design to better serve students through teaching.

\section{B. Direction of Physical Education Design}

Different courses are supported by different instructional design concepts. And different instructional design concepts will influence the value orientation of courses. The difference between instructional design and other theories is that it belongs to the designing direction. The theory of instructional design is a kind of science of design, because it provides guides for the task of designing learning experience. [3] Because the social structure, knowledge and institution of skill of designers objectively have different kinds of requirements when people are occupied in physical activities, people have different understandings for the value orientation of physical education curriculum. But the direction of the process of physical education design should be logical, rational and innovative. If we say design is a project, then gym teacher is the engineer of this design.

1)Rational designing direction: The rationalistic curriculum theory attaches importance to the transmission of human culture, and emphasizes the meaning and value of knowledge and departmental teaching and training. Instructional design is a kind of conception and assumption and it will encounter many problems in the "process" of execution. Design is a science that seeks the understanding for regulation. When implementing these regulations, design is closer to engineering science. [4] Physical education design has connection with extensive disciplinary knowledge. When designing, it's necessary to develop, evaluate and maintain, and formulate detailed and normative technical process that helps to realize the learning objectives of physical education according to principles of teaching science. With the help of this, we can accurately predict phenomenon in the future (such as the learners' behavior, teaching methods of the teacher). Rationalistic physical education curriculum design emphasizes taking universal, stable and basic knowledge and skills of physical education as the center of curriculum.

2)Innovative designing direction: The instructional design is described as a kind of creative process. In design, the richness of thoughts, the creativity and uniqueness of scheme that solves the problem all come from the creativity of designer. In the process of physical education design, designers rely on intuition to conclude factors that affect the design in the background and identify key information. [5] Problems that maybe appear in design become intuitive. The intuition makes quick response to the problem and then confirms potential strategies, so that different teaching results will be achieved and intuition becomes the key in innovation. Factors related to intuition are the explosive breakthrough of designers by accident on the basis of existing knowledge.

3)Orientation that rationality is compatible with innovation: To emphasize the compatibility between rationality and innovation in teaching is to make physical education design conform to science. When designers carry out design activities of physical education, it is impossible to 
use pure rationality and creativity to complete the design. Designers of physical education base on the objectives and directed logical thinking to filter, measure, try, choose or give up assumptions. "Intuition, creativity and logical thinking have play roles in the thinking of designers". [6] Through years of learning and training of gym skills and culture, gym teachers know clearly about the logical process of skills and knowledge that will be taught by them. In the process of integrating rationality and innovation, teachers not only need assumption, but also need to carefully analyze results of students' real thinking activities to regulate and control the development direction of knowledge to conform to their presupposed objectives. [7] Therefore, when implementing instructional design, teachers must complete logical sequence of knowledge and carry out innovative activities on the basis of ensuring that the sports knowledge taught by them is scientific and accurate.

\section{INTEGRATION OF PHYSICAL EDUCATION DESIGN}

In traditional physical education design, we pass on knowledge and skills about physical education to students through individuals or organizations (organizations mainly refer to: school of physical education, physical education department, and teaching group of physical education). Teaching plan of physical education is the main manifestation of instructional design. Teaching plan organically combines the idea of instructional design with hardware of teaching, which seems to be perfect combination. While some teaching plans of the present gym teachers mainly cover several key links such as teaching materials, teaching tasks, contents, and brief summaries. It can be observed from this that traditional methods and ideas of physical education are too simple. Physical education design is the most important field in teaching application, because the particularity of situational factors and organization in practical teaching, it demands physical education design must have special instructional design that is different from other teaching. The integration of physical education design is a kind of method to effectively design and create learning environment.

\section{A. Matching of Learners' Cognitive Style and Instructional Design}

Learners' cognitive style is the preferred and relatively stable attitude and way used by individuals to understand, store, convert and use information. [8] Learners' cognitive style is a variable dimension and learners use different ways to process information. Only when instructional design matches with learners' thinking or learning style, learners can achieve greater success. Therefore, instructional design should put emphasis on overall collaborative development of learners' cognitive style. The meaning of learning style of teachers is reflected in making teachers realize advantages and strengths of students in the information processing process. What's more, it can give full play to learning initiative and advantages of individual quality of learners who have individual differences and make every learner enjoy the advantages of education.

\section{B. Consistency of Instructional Design Situation and Teaching Practice}

Situation in learning environment must help students to construct meanings of learned information, which puts forward new demands for instructional design. That is to say, under the learning environment of constructivism, instructional design should not only consider the analysis of teaching aims, but also consider creating problems that make for the situation of students' constructing meaning.

\section{The Growth of Gym Teachers' Professional Literacy}

Gym teacher is the soul of physical education design. "Products" designed by them directly reflect teachers' personal ability. "Ability" refers to mental characteristics required by individuals to master and use knowledge and skills. How to reflect teachers' advanced ideas and methods that conform to students' development features in instructional design needs gym teachers to become talents with reasonable intelligent structure. At the same time, they should expand breadth, depth and speed of general knowledge, professional knowledge and skills mastered by them through various channels.

\section{Consider Carefully About the Methods of Instructional Design}

On the basis of the complexity and uncertainty of teaching system, Jonathan puts forward the basic principle of "student centered" instructional design from the perspective of hermeneutic, namely "pursue learners' understandings of problems and focus on learners' interpretation of problems". [9] Students' understanding and interpretation of problems have to consider teaching methods used by gym teachers in physical instructional design. Except for traditional methods, we should consider more about the aided teaching of multimedia and provide more advantageous platforms for students to understand and solve problems efficiently.

\section{PHYSICAL EDUCATION DESIGN AND LEARNING ENVIRONMENT}

Knowledge and skills are often acquired when individuals use knowledge and skills. [10] This is a relevant environment and developed by individuals who serve as members of the organization. In teaching environment of physical education and environment of instructional design, we should take problem solving as the central activity. Therefore, the application of learning theory and learning environment become one of the main parts of problem solving. From the perspective of gym teachers, one of the main parts of problem solving is the application of instructional design and this kind of application has procedural and heuristic characteristics. From the perspective of science of physical education, the main parts of problem solving are modeling and experiments in order to obtain prescriptive theory that combines teaching methods and learning methods. The learning environment of problem solving is very important. In this environment, learners can construct and acquire different knowledge and technologies through different activities of problem solving. 


\section{SELECTION OF TEACHING STRATEGIES}

\section{A. Learning From Examples}

Learning from examples is the core aspect of activities of problem solving as well as the basis of teaching. This teaching strategy is to make the most of examples of problem solving to promote students to consciously abstract these examples, for example: use multimedia to play different technical levels, let students themselves predict the level that they can reach and observe that the students will present what kind of problems at this level, and then improve, adjust and extend instructional design and make learners research and practice carefully.

\section{B. Construct Lifelike Learning Environment}

Merrill, the famous American expert in instructional design, believes that: instructional design is a technology to develop learning experience and learning environment. [11] Skills and culture of physical education that develop continuously make people can learn in the learning environment established. In this learning environment, learners must imagine what has happened in the "real" external environment, use their knowledge and skills to imagine what will happen to them. If the imagined information cannot be better understood or executed, learners should make time to learn and consult teachers before starting formal learning. In this way, students think the outside world, practice skills, and make themselves reach their goals as soon as possible through learning. Gym teachers should carefully choose learning situation according to knowledge and skills taught by them.

\section{Communicate with Students}

The communication mode and frequency between instructors and learners are decided by the location and characteristics of students' skills. In physical education or training, it's often observed that few students are in a special position (in general case, it refers to advantages of students' professional literacy and teachers' preferences.) Therefore, it is essential for us to develop self-instructional materials and improve teachers' professional quality. When communicating with students directly, teachers need carry through real-time instructional design.

\section{CONCLUSION}

Physical education design should be established under student-centered and learner-centered environment, provide interactive and incentive activities, meet unique learning interests and needs of individuals, make them learn under different levels of complexities and deepen their understanding. The total quantity of knowledge and skills dominated by gym teachers in specific group is so great that it provides countless flexible and powerful selection methods for physical education design. How to rein under the new historical background not only examines and weighs the wisdom of gym teachers but also systems and ideas in our physical education.

\section{REFERENCES}

[1] Rowland, G (1993).Design and Instructional Design, ETR\&D, 41(1), $79-91$

[2] Clark C, Peterson P. Teacher Thought Processes. In:Wittrock M.Handbook of research on teaching.3rd ed. New York: MacMillan, 1986

[3] Reigeluth, C.M (1999).Instructional-Design Theories and Models, Volume 2: A new paradigm theory. Mahwah, NJ: Lawrence Erlbaum Assoc

[4] Rowland, G (1993).Design and Instructional Design, ETR\&D, 41(1), $79-91$

[5] Translated and edited by Gao Wen. Design and Instructional Design, Foreign Education Information, 1997(2)

[6] Winn,W.(1997). Advantage of a Theory - based Curriculum in Instructional Technology, Educational Technology, 37(1)

[7] Zhang Kun. Research on Logical Orientation and Psychological Orientation Happened on the Basis of Knowledge [J], Journal of Chinese Society of Education (Curriculum and Teaching) 2011. 06

[8] Yao Jie. Discussion on the Influences of Teachers' Cognitive Style on Students' Cognitive Development [J], Journal of Jiangsu Institute of Education (Social Science), the 3rd ed. in 2011.

[9] Jonassen, D.H.et al.(1997). Certainty, Determinism, and Predictability in Theories of Instructional Design: Lessons from Science. Educational Technology.37(1)

[10] Gao Wen, Research on Instructional Design [J], Global Education Outlook, the 1st ed. in 2001

[11] Gao Rong, Analysis on the Concept and Function of Classroom Instructional Design, China School Physical Education [J], the 4th ed. in 2011 